\title{
PANDANGAN STEPHEN KRASHEN DALAM PEMEROLEHAN BAHASA DAN IMPLIKASINYA DALAM PEMBELAJARAN BAHASA ARAB
}

\begin{abstract}
Andri Warseto, Hani Nurlaeli Wijayanti, Cahya Edi Setyawan andrewarseto@gmail.com, haninurlaeliwijayanti@gmail.com, Cahya.edi24@gmail.com

UIN Mataram, IAI Nurul Hakim Lombok, STAI Masjid Syuhada
\end{abstract}

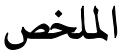

صاغ العديد من الخبراء الغربيين نظرية اكتساب اللغة. واحد منهم هو تشومسكي • يرى تشومسكي أن هناك فرقًا بين اكتساب اللغة وتعلم اللغة. الاثنان مرتبطان بالزمان والمكان . لكن هناك باكا واحد اسمه ستيفن كراثين يقول إنه لا يوجد فرق بين اكتساب اللغة وتعلمها أن العملية هي نفسها وتبداً من الولادة البشرية حتى نهاية الحياة. يتكلم البشر في التعليم أو التعلم أو أو الفصل الدراسي بشكل غير مباشر ولا يدركون أنهم يتعلمون لغة، لأن اللغة في

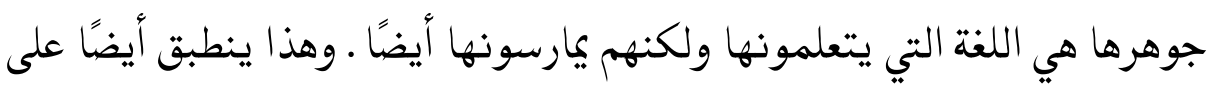
تعلم اللغة العربية. تفكير ستافن كراشين له آثار على عملية اكتساب اللغة العربية للطلاب في إندونيسيا بدءًا من شكل عملية التعلم، وتشكيل بيئة لغوية، ودور المعلمين والأنشطة الطلابية.

$$
\text { الكلمات المفتاحية : الظروف الطبيعية ، ستيفن كراشين }
$$

\section{Pendahuluan}

Penfield and Roberts (1959), peneliti dalam bidang neuroscince, menyatakan bahwa pada kondisi Critical period, anak 
Andri Warseto, Hani Nurlaeli Wijayanti, Cahya Edi Setyawan : Pandangan Stephen Krashen dalam Pemerolehan Bahasa dan Implikasinya dalam Pembelajaran Bahasa Arab

memiliki kapasias khusus untuk mempelajari bahasa, baik bahasa pertama (L1) maupun bahasa kedua (L2). ${ }^{63}$ Critical period berlangsung antara usia 6 tahun hingga 9 tahun. Pada masa ini anak akan lebih cepat menyerap exposure yang diterimanya. Exposure yang baik mutlak diperlukan untuk mencetak kompetensi berbahasa Inggris yang memadai. Guru sebagai fasilitator atau katalisator harus memiliki kemampuan yang memadai, baik dalam pemilihan kata dan pemakaiannya, intonasinya, serta ekspresi tubuhnya.

Pemerolehan bahasa secara alami tidak di sadari melalui pemahaman dan penggunaan bahasa dalam komunikasi yang bermakna. Proses ini terjadi sebagaimana bayi yang mulai mempelajari bahasa ibu mereka. Artinya mereka belajar dan mendapatkan bahasa tanpa mereka sadari. Sementara itu, Learning dimaknai sebagai berkembangnya kesadaran akan aturan bahasa. Dalam proses akuisisi, intake adalah merupakan faktor terpenting dalam sebuah pengajaran bahasa. Intake didapat siswa dari input melalui proses, yang salah satunya adalah dengan, penggunaan bahasa dalam komunikasi secara langsung dengan bahasa target.

Studi tentang pemerolehan bahasa sesungguhnya dari sejak dulu sudah dilakukan mulai. Banyak pakar barat yang mencetuskan teori-teorinya. Skinner, Chomsky, Piaget dan lain-

${ }^{63}$ Sanz, Cristina Ed, Mind and context in adult second language acquisition: methods, theory, and practice, USA: Georgetown University Press, 2005, hlm. 107 
Andri Warseto, Hani Nurlaeli Wijayanti, Cahya Edi Setyawan : Pandangan Stephen Krashen dalam Pemerolehan Bahasa dan Implikasinya dalam Pembelajaran Bahasa Arab

lainnya. Masing-masing memilik kekhasan sendiri-sendiri. Entah teori itu benar atau salah yang jelas mereka melakukan penelitian sebagai bukti ilmiahnya agar teorinya bisa diakui publik. Secara mudahnya, sesungguhnya apapun teorinya bahwa pemerolehan bahasa adalah hal yang alamiah yang akan dialami oleh manusia. Manusia secara tidak sadar akan berbahasa meskipun mereka tidak diberi tahu sedang belajar bahasa. Maka dari itu, ada pakar yang membahasa bahwa pemerolehan bahasa di mulai dengan proses alamiah atau natural dan itu tidak berpengaruh mau bahasa pertama atau bahasa kedua dan dimulai sejak lahir hingga akhir hayat. Tidak ada perbedaan yang signifikan antara sekat pemerolehan yang dianggap istilah bahasa pertama dan pembelajaran yang di anggap untuk pemerolehan bahasa kedua. Antara istilah keduanya sama. Maka dari itu perlu kiranya dibahas tentang pemikiran Staphen Krashen ini.

\section{Pemerolehan Bahasa Pertama dan Kedua (اكثساب اللغة الأولي والثانية)}

Dalam sejarah teori pemerolehan bahasa dan pembelajarannya, natural methode merupakan salah satu metode yang relatif masih baru. metode alamiah merupakan metode yang relatif baru. Bahkan, metode ini lebih muda usianya dibandingkan dengan communicative methode yang terkenal itu. Metode komunikatif berakar dari pandangan Chomsky tentang competence dan performance yang dipublikasikan pada tahun 1964, sedangkan sejarah natural methode dimulai pada tahun 1977. Pada tahun 1977, 
Andri Warseto, Hani Nurlaeli Wijayanti, Cahya Edi Setyawan : Pandangan Stephen Krashen dalam Pemerolehan Bahasa dan Implikasinya dalam Pembelajaran Bahasa Arab

Tracy Terrel, seorang guru bahasa Spanyol di California, mempublikasikan sebuah rancangan bagi filsafat pengajaran bahasa yang disebut dengan natural approach. Menurut Terrel, pendekatan tersebut merupakan upaya untuk merancang pengajaran bahasa yang mendayagunakan prinsip-prinsip alamiah yang diperoleh melalui penelitian tentang pemerolehan bahasa kedua. Rancangan Terrel ini berdampak positif bagi para praktisi pengajaran bahasa, mereka tergugah untuk melaksanakan penelitian dan menerapkan gagasan Terrel ini. Stephen D. Krashen salah satu diantara praktisi yang mengembangkamn gagasan Terrel ini. Dia merupakan praktisi dan peneliti pemerolehan bahasa di University of Southern California.

Ada dua pandangan Terrel dan Krashen tentang pemerolehan bahasa, yaitu: 1) pendekatan pembelajaran yang dirancang itu bersifat tradisional. Pengertian tradisional adalah pendekatan pembelajaran bahasa yang diselaraskan dengan proses pemerolehan bahasa sebab proses pemerolehan bahasa bersifat alamiah tanpa tuntutan kemampuan berbahasa target siswa seperti kemampuan penutur asli atau native speaker. Mereka berdua mengatakan: "Traditional approaches are defined as 'based on' the use of language in communicative situations without recourse to the native language" 64 , 2) Keempat istilah yaitu pendekatan, strategi, metode,

64 Richards \& Rodgers, Richadrs, Approachs and Methods in Language Teaching: A Description and Analisys, London: Cambridge Unversity Press, 1986, hlm.128 
Andri Warseto, Hani Nurlaeli Wijayanti, Cahya Edi Setyawan : Pandangan Stephen Krashen dalam Pemerolehan Bahasa dan Implikasinya dalam Pembelajaran Bahasa Arab

dan teknik itu disamakan pengertiannya (Natural Approach and Natural Method are synonymous terms). Oleh sebab itu, pengertian Natural Approach dapat diterjemahkan menjadi pendekatan alamiah, strategi alamiah, metode alamiah, atau bahkan teknik alamiah.

Natural methode juga memiliki kesamaan dengan Direct Methode. Aspek yang sama itu adalah dalam penggunaan istilah alamiah atau natural. Pengertian natural yang dianut dua orang pakar ini mengacu pada bagaimana seorang anak secara alamiah mampu menguasai bahasa melalui proses pemerolehan bahasa. Terrel dan Krashen mencoba mendayagunakan proses pemerolehan bahasa dan konteks pembelajaran bahasa. Meskipun demikian, dalam hal lain, metode alamiah ini berbeda dari metode langsung. Perbedaan itu terutama terletak pada pandangan para pengajar metode alamiah yang tidak menyetujui penggunaan monolog guru, pengulangan langsung, serta tanya-jawab langsung. Pengajur metode alamiah lebih mementingkan pemberian pajanan (exposure) atau pemberian masukan yang terpahami (comprehensible input). Di samping itu, penganjur metode alamiah cenderung berorientasi pada pengajaran berdasarkan pemahaman (comprehension-based learning), artinya tidak menuntut siswa mengunjukkan kemampuan produktif (berbicara dan menulis) sebelum guru meyakini bahwa siswa memiliki kemampuan pemahaman yang memadai. 
Andri Warseto, Hani Nurlaeli Wijayanti, Cahya Edi Setyawan : Pandangan Stephen Krashen dalam Pemerolehan Bahasa dan Implikasinya dalam Pembelajaran Bahasa Arab

Setiap anak manusia memakai strategi yang sama dalam memperoleh bahasa ibunya, hal ini merupakan pandangan semua pakar. Kesamaan ini tidak hanya dilandasi oleh biologi dan neurologi manusia yang sama tetapi juga oleh pandangan mentalistik yang menyatakan bahwa anak telah dibekali dengan bekal kemampuan bahasa secara alamiah pada saat dilahirkan. 65 Pemerolehan bahasa pertama terjadi apabila seorang anak manusia yang sejak semula tanpa bahasa dan kini dia mulai memperoleh satu bahasa. Bila bahasa pertama maka disebut "pemerolehan bahasa pertama ekabahasa" atau "monolingual first language acquisition". Sementara itu, bila seorang anak mempelajari bahasa setelah bahasa pertama yang dia peroleh maka disebut sebagai "pemerolehan bahasa pertama dwibahasa" atau "bilingual first language acquisition". Menurut Tarigan bahwa Pemerolehan bahasa kedua tidak sama dengan pemerolehan bahasa pertama. Pada pemerolehan bahasa pertama anak dalam keadaan tidak memiliki kompetensi bahasa sama sekali hingga pada masa perkembangan fisik dan psikisnya mereka mendapatkan pola bahasa dan mengembangkannya dengan alamiah.

Dalam pemerolehan bahasa kedua, Ellis menyebutkan bahwa ada dua tipe pemerolehan bahasa, yaitu 1) Tipe Naturalistik. Tipe ini paling banyak dialami dan ditemukan hampir di seluruh ujung dunia. Heterogenitas ras dan suku pendatang dikota-kota

65 Dardjowidjojo Sunyono, Psikolinguistik; Pengantar Pemahaman Bahasa Manusia, (Jakarta: Yayasan Obor Indonesia.), hlm. 243 
Andri Warseto, Hani Nurlaeli Wijayanti, Cahya Edi Setyawan : Pandangan Stephen Krashen dalam Pemerolehan Bahasa dan Implikasinya dalam Pembelajaran Bahasa Arab

besar akan mempengaruhi alamiahnya proses pemerolehan bahasa manusia. Hal ini dikarenakan beragamnya budaya dan bahasa, sehingga mempengaruhi perkembangan pemerolehan bahasa manusia itu. Manusia dengan berbagai ras adan suku itu dengan kekhasan bahasa daerahnya, akan menggunakan bahasa indonesia (bahasa kedua) ketika mereka berkumpuldengan keluarganya ${ }^{66}, 2$ ) Tipe Formal. Allan G Reynolds dalam tulisan "The McGill Conference In Honour of Wallace E. Lambert", menyatakan pengembangan pemerolehan dan pembelajaran bahasa akan berkembang efektif bila diaplikasikan dalam kehidipan sosial (naturalistic)67, idelanya tipe pemerolehan bahasa secara formal bisa mendapatkan output yang lebih baik daripada pola naturalistic. Tipe ini biasanya terjadi di dalam kelas dengan bimbingan seorang guru, materi, media dan alat bantu pembelajaran yang sudah dipersiapkan. Akan tetapi faktanya di indonesia masih kesulitan menggunakan bahasa kedua (inggris dan Arab) meskipun sudah mempelajarinya semenjak dari bangku sekolah dasar.

Menurut Carroll melalui Krashen tiga ada tiga komponen utama dalam kecerdasan bahasa. ${ }^{68}$ Ketiga komponen yang akan dijelaskan kemudian ini bisa diujikan melalui Language Aptitude

${ }^{66}$ Abdul Chaer dan Leoni Agustina, Sosiolinguistik: Perkenalan Awal, ( Jakarta: Rineka Cipta, 1995), hlm. 244.

67 The McGill Conferece In Honour of Wallace E. Lambert, Bilingualism, Multiculturalism, and Second Language Learning, Hillsdale, (New Jersey: Lawrence Elbraum Associates, Inc, Publisher, 1991), hlm. 186.

68 Stephen Krashen, Second Language Acquisition and Second Language Learning, (University of South Carolina, 1982), hlm. 19-21. 
Andri Warseto, Hani Nurlaeli Wijayanti, Cahya Edi Setyawan : Pandangan Stephen Krashen dalam Pemerolehan Bahasa dan Implikasinya dalam Pembelajaran Bahasa Arab

Battery (LAB) atau Modern Language Aptitude Test (MLAT). Ketiga komponen itu adalah sebagai berikut: 1) Phonemic coding ability adalah kemampuan untuk mengidentifikasi bunyi bunyi bahasa baru dan menyimpannya dalam memori, sehingga mereka bisa mengingat dan menggunakannya di kemudian hari, 2) Grammatical sensibility adalah kemampuan untuk mengetahui fungsi gramatikal kata dalam sebuah kalimat, contoh mengetahui subjek dan objek pada sebuah kalimat, 3) Inductive language learning ability adalah kemampuan untuk mengidentifikasi pola korespondensi dan hubungan antara bentuk dan makna.

Hubungan secara langsung antara kemahiran atau kecerdasan dan faktor-faktor attitudinal benar-benar ada, dan jika tujuan besar kita dalam mengajarkan bahasa adalah mengembangkan kemampuan untuk berkomunikasi, kita harus menyimpulkan bahwa faktor-faktor attitudinal (sikap bahasa) dan faktor-faktor motivational (motivasi) lebih penting daripada kecerdasan atau bakat. Hal ini terjadi karena pembelajaran secara sadar (conscious learning) hanya memiliki kontribusi yang kecil terhadap kemampuan berkomunikasi. ${ }^{69}$

Dari pemahaman diatas, dapat disimpulkan bahwa ada perbedaan secara prosedural dalam proses pemeroleha bahasa pertama dan kedua. Secara alamiyah pemerolehan bahasa pertama

69 Julio Segura, Aptitude, Attitude and Motivation Towards Language Learning (2011) http://www.slideshare.net/csclector/aptitude-attitude-andmotivation-towards-language-learning diakses 29 Juli 2020 
Andri Warseto, Hani Nurlaeli Wijayanti, Cahya Edi Setyawan : Pandangan Stephen Krashen dalam Pemerolehan Bahasa dan Implikasinya dalam Pembelajaran Bahasa Arab

bersifat alamiah dan non formal atau informal. Pemerolehan bahasa anak berjalan sesuai perkembangan fisik dan psikisnya dalam kehidupan. Secara alamiah anak akan menangkap pola-pola kebahasaan yang dia dapatkan pertama kali pada masa kanakkanaknya, entah itu bahasa ibunya, atau bahasa yang pertama kali dia dapatkan. Chomsky mengatakan bahwa anak memiliki sebuah chip dalam otaknya yang disebut dengan LAD (language acquisition device) yang bisa merekam bahasa yang nantinya seiring dengan perkembangan fisik dan psikisnya bahasa itu akan diucapkan ketika sudah masanya. Meskipun demikian tetap ada yang namanya lingkungan yang berperan untuk menstimulus secara alami, yaitu lingkungan dia berkehidupan dan dengan siapa dia berinteraksi dan berkomunikasi. Berbeda dengan pemerolehan bahasa kedua, yang tipe dan sifatnya secara prosedural lebih formal dan di setting dalam wadah yang disebut ta'lim (pembelajaran) dan tarbiyah (pendidikan) untuk tujuan tertentu. Dalam konteks masyarakat indonesia, hal ini bisa disebut belajar bahasa asing untuk tujuan tertentu seperti belajar bahasa Arab dan Inggris agar bisa ke luar negeri baik untuk bekerja ataupun untuk urusan Agama.

\section{Pemerolehan Bahasa Kedua Menurut Stephen Krashen}

Krashen berpendapat bahwa istilah pemerolehan bahasa tidak selalu identik digunakan untuk bahasa pertama (bahasa Ibu), istilah pemerolehan juga bisa di istilahkan pada bahasa kedua. 
Andri Warseto, Hani Nurlaeli Wijayanti, Cahya Edi Setyawan : Pandangan Stephen Krashen dalam Pemerolehan Bahasa dan Implikasinya dalam Pembelajaran Bahasa Arab

Selanjutnya Krashen membagi menjadi dua konsep inti perbedaan dalam belajar bahasa, yaitu:

\section{Pandangan Stephen Krashen Tentang Language Acquisition}

Pemerolehan bahasa adalah pendapatan bahasa yang mengacu pada proses alami, melibatkan manusia dengan belajar bahasa secara tidak sadar. Pemerolehan bahasa merupakan otentifikasi dari adanya interaksi nyata antara pelajar dengan orang-orang di lingkungan bahasa target, di mana pelajar sebagai pemain aktif. Hal ini mirip dengan anak yang belajar bahasa ibu mereka. Proses ini akan menghasilkan keterampilan fungsional dalam bahasa lisan tanpa tuntutan pengetahuan teoritis, dengan kata lain pelajar memiliki upaya untuk mengembangkan keterampilan untuk berinteraksi dengan orang asing serta menciptakan situasi komunikasi secara alami (natural communication situation) agar dapat memahami bahasa mereka, tanpa adanya tuntutan untuk menguasai teori. ${ }^{70}$

Sedangkan pembelajaran terlihat seperti kegiatan yang bersifat prosedural dan settingan sangat berbeda dengan pemerolehan yang berujung pada pengembangan komunikasi, kepercayaan diri pelajar. ${ }^{71}$ Sebagai contoh ketika seorang remaja yang tinggal di luar negeri selama satu tahun menjalani program pertukaran pelajar, mereka mendapatkan kefasihan lebih asli,

70 Keith Johnson, An Introduction to Foreign Language Learning and Teaching, (England: Pearson Education Limited 2001), p. 76

71 http://www.sk.com.br/sk-laxll.html diakses pada tanggal 1 Agustus 2020 pukul 11.00 WIB 
Andri Warseto, Hani Nurlaeli Wijayanti, Cahya Edi Setyawan : Pandangan Stephen Krashen dalam Pemerolehan Bahasa dan Implikasinya dalam Pembelajaran Bahasa Arab

dan memiliki pengucapan yang lebih baik daripada mereka yang belajar bahasa di dalam kelas karena sifatnya yang informal dan alami. ${ }^{72}$ Dalam pembelajaran bukan tentang bahasa saja, namun mengubah informasi tersebut menjadi pengetahuan lewat upaya intelektualnya kemudian menyimpannya dengan cara menghafal. Hal ini akan membuat pelajar menjadi kurang akrab dengan bahasa itu sendiri. Dari pandangan inilah Krashen melahirkan lima hipotesis yang akan di jelaskan selanjutnya. ${ }^{73}$

\section{Pandangan Stephen Krashen Tentang Language Learning}

Pembelajaran bahasa sering disebut sebagai pendekatan tradisional, dan saat ini, pendekatan ini masih sangat umum dipraktikkan oleh sekolah-sekolah di seluruh penjuru dunia. Perhatian pembelajaran difokuskan pada bahasa dalam bentuk tertulis. Tujuannya adalah agar pelajar memahami struktur dan aturan bahasa, membedahnya serta menganalisisnya, selain itu diperlukan usaha intelektual dan penalaran deduktif kepada para pelajar. Mudahnya, pendekatan dalam bentuk pembelajaran, memiliki ciri: a) mengesampingkan komunikasi, komunikasi di anggap tidak begitu penting, b) teknik belajar mengajar hanya bersandar pada silabus, hal ini akan memberi kesan kaku dan kurang imajinatif, c) banyak berkutat hanya

72 Stephen Krashen, Principle and Practice in Second Language Acquisition, (University of Southem California: Pergamon Press Inc. 1982), p. 10.

73 Marysia Johnson, a Philosophy of Second Language Acquisition, (London: Yale University Press 2004), p. 46 
Andri Warseto, Hani Nurlaeli Wijayanti, Cahya Edi Setyawan : Pandangan Stephen Krashen dalam Pemerolehan Bahasa dan Implikasinya dalam Pembelajaran Bahasa Arab

pada teori, aturan-aturan kebahasaan (Grammatical Rules) dan tidak dibarengi dengan praktik, d) guru memiliki otoritas utama, pelajar hanya sebagai participant, bergerak secara pasif, e) pelajar hampir tidak pernah menguasai penggunaan struktur dalam percakapan. ${ }^{74}$

\section{Hipotesis Stephen Krashen dalam Pemerolehan Bahasa} (Ikhtisabul Lughoh)

Krashen melahirkan lima hipotesis, hipotesis ini diterbitkan pertama kali olehnya pada tahun 1980-an, yaitu: ${ }^{75}$

a. Hipothesis Pemerolehan - Pembelajaran ${ }^{76}$

Sebagaimana yang telah dijelaskan sebelumnya bahwa hipotesis ini mengacu kepada bagaimana bahasa kedua sebagai sebuah sistem yang deperoleh atau dipelajari. Sistem yang diperoleh mengandung maksud bahwa bahasa dikuasai melalui proses bawah sadar (unconscious mind). Dalam bukunya yang berjudul "Principle and Practice in Second Language Acquisition", Krashen menekankan bahwa pemerolehan adalah proses tidak sadar "Acquisition is a subconscious procces". Lebih rincinya, Krashen menjelaskan bahwa, pelajar tidak akan menyadari bahwa ia belajar bahasa,

74 2http://www.sk.com.br/sk-laxll.html, Accessed 10th of Juli 2020, 09.45 AM

75 Marysia Johnson, a Philosophy of Second Language Acquisition, (London: Yale University Press 2004), p. 46

76 Stephen Krashen, Effective Second Language Acquisition, the aticle taken at www.SDResources.org 29nd juli 2020, 11:25 AM 
Andri Warseto, Hani Nurlaeli Wijayanti, Cahya Edi Setyawan : Pandangan Stephen Krashen dalam Pemerolehan Bahasa dan Implikasinya dalam Pembelajaran Bahasa Arab

tetapi mereka hanya meyadari bahwa mereka sedang berkomunikasi. Singkat kata, pemerolehan bahasa terjadi ketika pelajar berkomunikasi dan terus berkomunikasi secara natural atau alami, tidak terfokus kepada aturan-aturan kebahasaan "not consciously aware of the rules". 77 Sedangkan pengkoreksiannya atau evaluasinya juga terjadi secara alami sesuai dengan konteksnya. ${ }^{78}$

Selanjutnya, kemampuan pendapatan bahasa ini tidak akan musnah dengan bertambahnya usia atau pada masa pubertas, "...the ability to pick up the language does not disappear at puberity" walaupun sudah berusia dewasa, pemerolehan masih sangat mungkin dilakukan dan terjadi. Malahan Krashen menganggap bahwa proses pemerolehan akan sangat kuat bila diterapkan sewaktu dewasa. ${ }^{79}$ Berbeda dengan sebelumnya, sistem yang dipelajarai (pembelajaran) mengandung maksud kebalikannya, yaitu bahasa dikuasai melalui proses sadar, hal ini diamini oleh Krashen, ia berpendapat bahwa istilah belajar merujuk kepada pengetahuan secara sadar "... The term (learning) henceforth to refer to conscious knowledge of second language". Dengan kata

\footnotetext{
77 Stephen Krashen, Principle and Practice in Second Language, Op.Cit., p.10

${ }^{78} \mathrm{H}$ Douglas Brown, Pinciples of Language Learning and Teaching, fourth edition, (New York: Addison Wesley Longman Inc, 2000), p. 277-278. $10-11$.

${ }^{79}$ Stephen Krashen, Principle and Practice in Second Language, Op.Cit., p.
} 
Andri Warseto, Hani Nurlaeli Wijayanti, Cahya Edi Setyawan : Pandangan Stephen Krashen dalam Pemerolehan Bahasa dan Implikasinya dalam Pembelajaran Bahasa Arab

lain bahasa dikuasai melalui proses dan pengkondisian yang terjadi secara formal, seperti belajar di kelas, kursus dll dengan mengetahui aturan kebahasaan, sinonim kata, dan belajar secara kontekstual. Adapun pengoreksiannya terjadi dengan melakukan latihan-latihan dan pembiasaan.

Hal-hal yang telah tersebut tadi, akan berguna pada pelajar sebagai sensor ucapan-ucapan mereka sebelum memproduksi kata. ${ }^{80}$ Tapi sekali lagi, Krashen memihak proses pemerolehan sebagai proses belajar bahasa yang meyakinkan, sebab menurutnya maksud inti dari mempelajari bahasa adalah kebisaan pelajar dalam berkomunikasi bahasa target, dan pemerolehan menghasilkan komunikasi yang sangat baik. ${ }^{81}$

Dalam proses pemerolehan bahasa Arab di indonesia kiranya teori ini akan bisa di terapkan jika sekolah atau lembaga bahasa yang mana anak-anak belajar didalamnya didesain se alamiah mungkin dengan berbagai pendekatan yang mengacu kepada humanisme dan naturalisme. Perlu kiranya bahasa Arab menjadi bahasa yang bisa digunakan

${ }^{80}$ Ian Lamb, "Fudamental of Second Language Acquisition Theory and its Application to Beginning and Intermediate Language Teaching (on Stephen Krashen)" in The Journal of Tesol -France Volume VIII Number 3, Autumn 1988 , p. 36.

81 Stephen Krashen, Second Language "Standart for Success": Out of touch with Language Acquisition Research, the article taked from http://www.sdkrashen.com/articles/standards/ index.html accesed at 30 Juli 2020, 10:15 PM 
Andri Warseto, Hani Nurlaeli Wijayanti, Cahya Edi Setyawan : Pandangan Stephen Krashen dalam Pemerolehan Bahasa dan Implikasinya dalam Pembelajaran Bahasa Arab

berinteraksi dalam kehidupan sehari-hari disekolah. Idealnya siswa juga harus belajar dengan rileks tanpa paksaan dan tanpa tekanan untuk berbahasa Arab. Untuk membuat suasana belajar menjadi rileks guru bisa menggunakan pendekatan Quantum Learning yaitu mendesain kelas agar menarik dan menggugah siswa untuk semangat berbahasa Arab atau menggunakan musik-musik islami berbahasa Arab agar siswa merasa nyaman dan tenang hatinya.

Di dalam perkembangannya, pemerolehan bahasa Arab sebagai bahasa kedua siswa di indonesia selayaknya mereka mendapatkan secara alamiah adalah seperti di pondok-pondok pesantren yang memang di pesantren itu didesain untuk berbahasa Arab seperti pondok-pondok modern Gontor Ponorogo, Pabelan Magelang, Guyangan Pati, Darunnajah Tangerang, Walisongo Ponorogo dan sebagainya. Di pondok-pondok ini biah lughawiyah terbentuk secara alami karena santrinya (siswanya) juga berkomunikasi secara alami. Bahasa Arab sebagai bahasa kedua mereka gunakan untuk berkomunikasi sehari-hari layaknya bahasa pertama (bahasa Indonesia). Jika merujuk pada teori dan pendapat Stephen Krashen yang mengatakan pemerolehan bahasa secara alami tanpa ada setingan maka sesungguhnya jika bahasa Arab itu di pelajari untuk berbahasa bukan untuk dipelajari apa itu bahasa, maka sesungguhnya di pondok-podok pesantren 
Andri Warseto, Hani Nurlaeli Wijayanti, Cahya Edi Setyawan : Pandangan Stephen Krashen dalam Pemerolehan Bahasa dan Implikasinya dalam Pembelajaran Bahasa Arab

modern inilah teori krashen secara tidak langsung sudah diterapkan.

Bahasa Arab digunakan layaknya bahasa Ibu (indonesia) tanpa berfikir apakah bahasa yang digunakan itu secara struktural atau kaidah benar atau salah, namun yang pasti secara tujuan dan makna konteksnya tepat sasaran antara si pembicara dan si pendengar (lawan bicara). Hal ini berdampak pada munculnya bahasa Arab lokal (bahasa Arab Slank) yang mana hanya komunitas tertentu yang memahaminya. Dalam kajian psikolinguistik hal ini berkembang dan disebut sebagai bahasa Slank, yang mana didalamnya terjadi proses alih kode ataupun campur kode.

Dalam hal ini setidaknya Krashen telah menunjukkan bahawa pemerolehan bahasa dan pembelajaran bahasa adalah merupakan hal yang sama dan bisa terjadi dalam keadaan apapun tanpa terikat ruang, waktu, dan masa yang dimulai dari sejak lahir sampai liang lahat (sepanjang hayat). Pemerolehan bahasa bisa dilakukan salah satunya dalam kegiatan pembelajaran bahasa dan pembelajaran bahasa merupakan proses alamiah yang mana kadang siswa sendiri tidak menyadari kalau mereka sedang belajar bahasa karena melalui proses berbahasa (bahasa digunakan untuk berkomunikasi) di dalam sekolah atau ruang kelas. 
Andri Warseto, Hani Nurlaeli Wijayanti, Cahya Edi Setyawan : Pandangan Stephen Krashen dalam Pemerolehan Bahasa dan Implikasinya dalam Pembelajaran Bahasa Arab

b. Hipotesis pemantauan (Monitor Hypothesis)

Maksud dari hipotesis ini adalah, setiap manusia dalam proses internal bahasa memiliki monitor yang berfungsi sebagai editing serta pengoreksi. Contohnya dalam belajar bahasa Arab terdapat aturan-aturan kaidah seperti perbedaan penggunaan kata untuk laki-laki dan perempuan (mudakkar muannatz), penggunaan tenses atau waktu (madhi, mudhari, amr dsb) bentuk kalimat (tawabi, sifat mausuf, na'at man'ut). Proses manusia berbahasa akan secara otomatis mengikuti kaidah ini, meskipun proses ini tidak bisa serta merta terjadi diawal mula belajar, namun secara alamiah akan terbentuk karena adanya kebiasaan-kebiasaan dalam pola berbahasa yang mereka terima dan itu dinyatakan sebagai aturan yang telah disepakati. Kesepakatan aturan itu juga awalnya dimulai dari apa yang disebut suka-suka (arbitrer) dan berjalan seperti sesuatu yang disepakati secara alamiah semacam adat yang dihukumkan (al-adah muhakkamah). Inilah yang disebut hipotesis pemantauan atau monitoring yang dilakukan oleh otak manusia sebagai pusat kebahasaannya.

Monitor akan muncul dalam pikiran seseorang untuk mempertimbangkan kapan pelajar menggunakan atauran atau kaidah hal-hal diatas. Hipotesis monitor berpendapat bahwa pemerolehan dan pembelajaran digunakan dengan cara yang sangat kompleks dan spesifik. Biasanya 
Andri Warseto, Hani Nurlaeli Wijayanti, Cahya Edi Setyawan : Pandangan Stephen Krashen dalam Pemerolehan Bahasa dan Implikasinya dalam Pembelajaran Bahasa Arab

pemerolehan memulai dengan membuat para pelajar berucap atau berbicara bahasa kedua (bahasa target) dan bertanggung jawab atas kefasihan dalam berbicara "acquisition "initiates" our utterances in a second language and is responsible for our fluency". ${ }^{82}$ Sedangkan belajar memiliki hanya satu fungsi, yaitu sebagai monitor atau editor "Learning has only one function, and that is as a Monitor." Walaupun dimasukkan di dalamnya permainan (games) atau belajar sambil bermain, tetap saja ia hanya melakukan perubahan dalam ucapan.

Dalam proses pembelajaran bahasa Arab, agaknya proses pemantauan ini membutuhkan seorang guru yang berfungsi sebagai pemonitor dan pengontrol proses alamiyah berbahasa Arab yang sedang berlangsung dalam bingkai sekolah atau pesantren. Hal ini bertujuan untuk mengembangkan berbahasa Arab siswa dan melatih siswa untuk benar dalam berbahasa Arab. Jika merujuk kepada alamiahnya pemerolehan bahasa sendiri, maka sebenarnya guru juga merupakan salah satu komponen dari lingkungan.

c. Hipotesis Alamiah (Natural Hypothesis Order)

Dalam hipotesis ini Krashen menyatakan bahwa struktur bahasa diperoleh dengan urutan ilmiah yang dapat diperkirakan, beberapa struktur tertentu cenderung muncul lebih awal dari struktur yang lain dalam pemerolehan bahasa.

82 Stephen Krashen, Principle and Practice in Second Language, Op.Cit., p. 
Andri Warseto, Hani Nurlaeli Wijayanti, Cahya Edi Setyawan : Pandangan Stephen Krashen dalam Pemerolehan Bahasa dan Implikasinya dalam Pembelajaran Bahasa Arab

Contohnya ada pada struktur fonologi, dalam struktur fonologi anak cenderung memperoleh vokal-vokal seperti (a) sebelum akhirnya menyentuh vokal (i) dan (u). Konsonan depan lebih dahulu dikuasai oleh anak daripada konsonan belakang. Urutan alamiah seperti ini tidak saja terjadi pada masa kanak-kanak tapi juga terjadi pada masa dewasa.

Dalam hipotesis ini, Krashen menyatakan bahwa pemerolehan struktur gramatik berlangsung dalam uruturutan yang dapat diramalkan. Hasil penelitian tentang pemerolehan bahasa Arab membuktikan bahwa struktur gramatik (nahwu dan sharf) tertentu diperoleh sebelum struktur gramatika tertentu (nahwu dan sharf) lainnya. Misalnya pemerolehan jumlah atau kalimat tidak akan didapat kecuali setelah tarkib (tarkib na'ti, tarkin idhafi, dsb). Sama seperti halnya dalam ilmu linguistik, misalnya pemerolehan tingkat klausa tidak mungkin berlangsung sebelum pemerolehan tingkat frase. Hal itu berlaku baik pada pemerolehan bahasa pertama maupun kedua.

Demikian juga dalam hal kesalahan berbahasa. Kesalahan berbahasa yang dilakukan anak dalam proses pemerolehan bahasa pertama akan cenderung dilakukan juga dalam pemerolehan bahasa kedua atau bahasa apa pun yang dipelajari siswa. Contoh dari hal ini adalah kesalahan penerjemahan yang dilakukan oleh siswa di indonesia. Rasa terjemahan siswa indonesia lebih cenderung ke dalam bahasa 
Andri Warseto, Hani Nurlaeli Wijayanti, Cahya Edi Setyawan : Pandangan Stephen Krashen dalam Pemerolehan Bahasa dan Implikasinya dalam Pembelajaran Bahasa Arab

ibu (bahasa indi=onesia dibanding bahasa sasaran (bahasa Arab). Jika ditinjau ulang secara budaya dan peradaban bahasa Arab jauh berbeda dengan bahasa Indonesia karena memang bukan satu rumpun kebahasaan. Maka tentunya hal ini mempengaruhi kemampuan dan gaya menerjemahkan siswa indonesia. Ini merupakan hal alamiah dalam proses pemerolehan bahasa dan umum terjadi.

d. Hipotesis Masukan (Input Hypothesis)

Hipotesis ini menjelaskan bahwa pembelajaran bahasa kedua dinggap akan terjadi jika siswa yang mendapatkan informasi atau pengetahuan setingkat lebih tinggi dari pada yang telah dikuasainya. ${ }^{83}$ Rumusan hipotesis masukan digunakan untuk menjelaskan hubungan antara wacana yang telah dihadirkan terhadap siswa dan apa yang telah diperoleh siswa. Hipotesis ini terkait dengan empat hal. Pertama, hipotesis masukan hanya dikaitkan dengan proses pemerolehan bahasa, bukan pembelajaran bahasa. Kedua, cara terbaik seseorang menguasai bahasa adalah dengan jalan memahami masukan yang memiliki tingkat kesukaran tertentu di atas tingkat penguasaan struktur yang dimiliki orang itu (rumusan yang lazim digunakan adalah 1 + I. Angka 1 menunjukkan tingkat penguasaan struktur yang telah dimiliki individu atau siswa, sedangkan I adalah tingkat

${ }^{83}$ Muriel Saville - Troike, Op.Cit., p. 45. 
Andri Warseto, Hani Nurlaeli Wijayanti, Cahya Edi Setyawan : Pandangan Stephen Krashen dalam Pemerolehan Bahasa dan Implikasinya dalam Pembelajaran Bahasa Arab

kesukaran yang baru yang hendaknya terdapat dalam masukan atau input.

Ketiga, kemampuan berbicara secara cermat tidak akan berkembang secara mendadak, melainkan melalui proses bertahap, terutama setelah individu atau siswa telah memiliki kompetensi linguistik yang memadai yang terutama disebabkan oleh adanya masukan-masukan yang terpahami. Keempat, jika secara berkelanjutan individu atau siswa memperoleh masukan yang terpahami secara memadai, maka konsep $1+\mathrm{I}$ akan berkembang secara otomatis. Masukan yang terpahami lazimnya berupa tuturan yang dipahami siswa berdasarkan konteks yang digunakan. Tuturan-tuturan itu, misalnya tuturan guru (lisan maupun tertulis) cenderung merupakan masukan yang terpahami dan menantang jika mengandung tingkat kesukaran tertentu, di atas pemahaman siswa/individu.

e. Hipotesis Efektif Filter (Effective Filter Hypothesis)

Dalam hipotesis ini Stephen Krashen menjelaskan bahwa setiap manusia memiliki saringan efektif atau yang biasa disebut dengan (Effective Filter). ${ }^{84}$ Saringan inilah yang memberikan rasa takut, malu pada seorang pelajar. Seorang pelajar bahasa yang memiliki motivasi tinggi, kepercayaan tinggi, dan kecemasan lebih rendah, akan lebih mungkin

84 Ibid. p. 31-32. 
Andri Warseto, Hani Nurlaeli Wijayanti, Cahya Edi Setyawan : Pandangan Stephen Krashen dalam Pemerolehan Bahasa dan Implikasinya dalam Pembelajaran Bahasa Arab

untuk berhasil dalam pemerolehan bahasa, tapi sebaliknya jika pelajar bahasa tidak memiliki beberapa hal yang telah tersebut diatas dalam dirinya maka terwujudlah sebuah variabel emosional yang positif. Selanjutnya, menurut Krashen, saringan atau filter ini akan menghambat siswa menerima atau mereproduksi bahasa. Contohnya jika ada seorang pelajar tidak suka dengan belajar bahasa Arab, maka saringan atau filter pada pelajar tersebut akan semakin menyempit, begitu pula jika benci terhadap pengajar, diolokolok, jika pelajar melakukan kesalahan dalam berbahasa. Hal ini nantinya akan menjadi problem pelajar, sebab perkembangan psikologisnya yang semakin peka terhadap lingkungannya.

Krashen dalam bukunya yang berjudul Second Language Acquisition and Second Language Learning menyatakan bahwa ada empat faktor yang mempengaruhi pemerolehan bahasa kedua, yaitu a) Motivasi. Pembelajar dengan motivasi yang besar pada umumnya dapat memperoleh bahasa kedua dengan baik. Senada dengan ini, Gardner (1985) mengatakan tentang pentingnya motivasi dalam mempelajari bahasa kedua, yaitu: "sejauh mana pembelajar mencoba atau berusaha untuk belajar karena keinginan untuk melakukannya dan kepuasan dalam belajar bahasa kedua".

Krashen (1988) sendiri membagi motivasi menjadi dua jenis, yaitu integrative dan instrumental. Integrative motivation 
Andri Warseto, Hani Nurlaeli Wijayanti, Cahya Edi Setyawan : Pandangan Stephen Krashen dalam Pemerolehan Bahasa dan Implikasinya dalam Pembelajaran Bahasa Arab

mendorong pembelajar untuk berbicara bahasa kedua. Disini, pembelajar tertarik untuk belajar dan ikut serta dalam komunitas tertentu. Sedangkan Instrumental motivation menekankan pada pembelajar berkeinginan untuk memperoleh kelancaran dalam bahasa kedua karena tujuan tertentu, seperti mendapatkan pekerjaan, belajar ke luar negeri, dan lain-lain. Dörnyei (1994) menyebutkan bahwa ada tiga set komponen motivasi. 1) course-specific motivational components yang terdiri dari silabus, materi pengajaran, metode pengajaran, dan tugas belajar; 2) teacher-specific motivational components yang terdiri dari teacher personality, teaching feedback, dan hubungan dengan siswanya; 3) groupspecific motivational components yang terdiri dari dynamics of the learning group, goal-orientedness, norm and reward system, group cohesion, classroom goal structures. 85

Faktor yang kedua adalah attitude. Attitude merupakan hal terpenting dalam memperoleh dan belajar bahasa dengan situasi tertentu. Faktor ketiga adalah kecemasan (anxiety).. Situasi yang paling menguntungkan untuk keberhasilan pembelajar bahasa kedua adalah tingkat kecemasan (anxiety). Brown (2000) menyatakan bahwa kecemasan bersifat permanen jika kecemasan itu cenderung

${ }^{85}$ Lihat di Alwazir Abdusshomad, AFFECTIVE FILTER TERHADAP PENGAJARAN BAHASA KEDUA (BAHASA ARAB), Jurnal Aviasi Langit Biru, Volume 5, Nomor 12, Oktober 2012, hlm. 47-53 
Andri Warseto, Hani Nurlaeli Wijayanti, Cahya Edi Setyawan : Pandangan Stephen Krashen dalam Pemerolehan Bahasa dan Implikasinya dalam Pembelajaran Bahasa Arab

ke arah kuatir yang berlebihan. Banyak pembelajar mengalami kecemasan yang berlebihan terhadap segala sesuatu. Faktor yang terakhir adalah selfconfidence. Terrell (Utari, 1988: 83) menyatakan bahwa seorang pembelajar yang memiliki kepercayaan diri yang tinggi cenderung lebih berhasil dalam memperoleh bahasa kedua, ketimbang pembelajar yang tidak percaya pada diri sendiri kurang berhasil dalam memperoleh bahasa kedua. Maka dari itu, kepercayaan diri merupakan aspek dalam perilaku manusia.

Merujuk pada ilmu psikolinguistik, ada sebuah teori mentalistik yang menyebutkan bahwa proses berbahasa manusia mengalami kegiatan yang melibatkan mental atau psikis, di dalam proses berbahasa ada faktor psikis internal kebahasaan yang mempengaruhi cara berbahasa dalam emosi (marah, sedih, gembira, bahagia) yang kemudian di dalam ilmu linguistik disebut hal dalam kajian cross cultural understanding. Ada juga faktor eksternal yang berupa keberanian dan ketakutan siswa akan berbahasa karena di pengaruhi oleh image sosial tentang kesalahan berbahasa, bahwa berbahasa itu harus menggunakan kaidah nahwu yang benar, padahal lupa bahwa secara alamiah dalam berbahasa faktor yang terpenting adalah penyampaian makna konteks dan tujuan berkomunikasi antara manusia. 
Andri Warseto, Hani Nurlaeli Wijayanti, Cahya Edi Setyawan : Pandangan Stephen Krashen dalam Pemerolehan Bahasa dan Implikasinya dalam Pembelajaran Bahasa Arab

\section{Implikasi Pandangan Stephen Krashen Terhadap Pembelajaran}

\section{Bahasa Arab}

Berangkat dari pemikiran Krashen ini, tentunya berimplikasi terhadap pembelajaran bahasa Arab. Pembelajaran bahasa Arab bagian dari pembelajaran bahasa yang di dalamnya dibahas tentang bagaimana proses pemerolehan bahasa. Di perguruan tinggi, pemerolehan bahasa juga masuk dalam kajian mata kuliah psikolinguistik. ADA beberapa hal dampak dari pemikiran krashen ini, yaitu:

1. Dalam proses pembelajaran bahasa Arab, diharapkan guru (lingkungan) mampu menyajikan masukan yang terpahami sebanyak mungkin. Artinya guru sebagai pengajar berfungsi sebagai fasilitator yang mampu memberikan materi sebagai masukan terbaik untuk siswa yang berhubungan dengan pola, kata, kalimat bahasa Arab. Maka dari itu dalam proses pemerolehan bahasa ada andil lingkungan didalamnya. Adapun guru merupakan bagian dari lingkungan yang mampu menstimulus siswa untuk berbahasa Arab.

2. Bantuan terhadap siswa atau pembelajar untuk mengembangkan kemampuan memahami bahasa Arab sangat diharapkan. Alat-alat bantu visual, misalnya, dapat digunakan untuk menampilkan pajanan (discourse) tentang kosakata daripada siswa dijejali teori-teori ketatabahasaan. Dalam hal ini, tentunya wasailu at-ta'lim penting dalam proses pembelajaran bahasa Arab. Dengan wasailul at-ta'lim siswa lebih mudah 
Andri Warseto, Hani Nurlaeli Wijayanti, Cahya Edi Setyawan : Pandangan Stephen Krashen dalam Pemerolehan Bahasa dan Implikasinya dalam Pembelajaran Bahasa Arab

memperoleh bahasa Arab karena hal itu membantu siswa dalam memahami materi kebahasaaraban.

3. Fokus pembelajaran dalam kelas hendaknya adalah aktivitas menyimak dan membaca, sedangkan kemampuan berbicara dan menulis akan berkembang secara perlahan dan berkelanjutan sejalan dengan kemampuan memahami itu.

4. Untuk memperendah saringan afektif, siswa hendaknya selalu diarahkan untuk terlibat dalam komunikasi bahasa Arab yang bermakna, bukan pada bentuk-bentuk bahasa bahasa Arab. Sejalan dengan itu, masukan yang dikembangkan guru hendaknya merupakan masukan yang menarik sekaligus menantang.

Pemikiran Krashen ini juga berdampak pada aspek-aspek yang mempengaruhi proses pemerolehan bahasa Arab, adapun aspek-aspek itu sebagai berikut:

1. Aspek Alamiah. Siswa Indonesia dalam belajar atau memperoleh bahasa Arab tidaklah mudah karena bukan bahasa Ibu. Namun bukan bukan berarti ini menjadi penghambat untuk memperoleh bahasa Arab. Alamiah saja bahwa berbahasa Arab seperti berbahasa Indonesia. Siswa akan berbahasa Arab jika mereka membutuhkan secara alamiah, sampai mereka tidak sadar ketika belajar bahasa Arab sebenarnya mereka sedang mempraktekkan berbahasa Arab. Menurut Chomsky anak terlahir dengan seperangkat prosedur dan aturan bahasa yang dinamakan Language Acquisition Device. potensi dasar ini akan 
Andri Warseto, Hani Nurlaeli Wijayanti, Cahya Edi Setyawan : Pandangan Stephen Krashen dalam Pemerolehan Bahasa dan Implikasinya dalam Pembelajaran Bahasa Arab

berkembang secara maksimal setelah mendapat stimulus dari lingkungannya. ${ }^{86}$

2. Aspek Perkembangan Kognitif. Dalam pembelajaran dan pemerolehan bahasa ternyata tidak bisa dipungkiri ada aspek kecerdasan atau perkembangan kognitif yang mempengaruhi kemampuan siswa dalam berbahasa Arab. Siswa yang perkembangan otaknya normal lebih mudah menerima bahasa Arab ketimbang siswa yang memiliki kekurangan dalam perkembangan kognitifnya. Perkembangan bahasa dan perkembangan kognitif pada anak memiliki hubungan yang komplementer. Piaget berpendapat bahwa komentar spontan anak dalam pemerolehan bahasa memberikan petunjuk berharga untuk memahami pemikiran mereka, tanpa memiliki ketertarikan pada benar atau salahnya komentar anak tersebut, melainkan bentuk logika dan alasan apa yang digunakan anak itu untuk mengungkapan pemikiran mereka dalam pemeroleh bahasa (Fernandez et al., 1981). ${ }^{87}$

3. Faktor Latar Belakang Sosial, dimana keluarga, kelompok sosial, serta lingkungan budaya penjadi perbedaan yang cukup serius dalam pemerolehan bahasa pada anak. Ini berhubungan dengan

86 Lihat dalam Shafa, Teori Pemerolehan Bahasa dan Implikasinya dalam Pembelajaran, Jurnal Dinamika Ilmu, 2012, https://doi.org/10.21093/di.v12i2.61, hlm. 3

${ }^{87}$ Fernandez, R. M., Singer, D. G., \& Revenson, T. A, A Piaget Primer: How a Child Thinks, Rocky Mountain Review of Language and Literature, https://doi.org/10.2307/1347747, 1981, p. 13 
Andri Warseto, Hani Nurlaeli Wijayanti, Cahya Edi Setyawan : Pandangan Stephen Krashen dalam Pemerolehan Bahasa dan Implikasinya dalam Pembelajaran Bahasa Arab

lingkungan berbahasa atau biah lughawiyah. Biah lughawiyah didapatkan dari lingkungan keluarga, sekolah dan masyarakat. Jika tiga hal itu memberikan pendidikan dan kedisiplinan yang baik dalam belajar bahasa Arab, maka hasilnya siswa akan mudah dalam memperoleh bahasa Arabnya. Maka sebenarnya lingkungan yang bagus untuk belajar bahasa Arab adalah pondok pesantren modern yang menganut sistem bilingual atau lingkungan kursus bahasa Arab yang mana disitu menggunakan bahasa Arab untuk kegiatan sehari-hari, atau bisa langsung belajar di negeri Arab seperti di mekah, madinah, jeddah, mesir,dan sebagainya.

4. Faktor Keturunan, diantaranya jenis kelamin, intelegensi masing-masing anak, serta kepribadian dan gaya pemerolehannya. Ada sebagian pengaruh gen dalam pemerolehan bahasa siswa. Anak keturunan orang Arab tentunya lebih mudah dalam berbahasa Arab, meskipun juga ada faktor kecerdasan dari orantuanya juga mempengaruhi pemerolehan bahasa Anak.

\section{Kesimpulan}

Pemikiran Krashen secara garis besar berisi tentang pendapat bahwa proses pemerolehan bahasa adalah proses alamiah yang dialami oleh manusia dalam kehidupannya sehari-hari. Tidak ada perbedaan yang signifikan antara pemerolehan bahasa dan pembelajaran bahasa, keduanya tidak terikat waktu dan ruang. 
Andri Warseto, Hani Nurlaeli Wijayanti, Cahya Edi Setyawan : Pandangan Stephen Krashen dalam Pemerolehan Bahasa dan Implikasinya dalam Pembelajaran Bahasa Arab

Dalam pembelajaran bahasa ada proses pemerolehan bahasa begitu pula pembelajaran bahasa sendiri merupakan bagian dari pemerolehan bahasa. Pemikiran krashen ini memiliki arti penting dalam proses pemerolehan dan pembelajaran bahasa Arab meliputi peran guru sebagai pemantau dan pembentukan biah lughawiyah, serta pembentukan komunitas bahasa Arab baru. 
Andri Warseto, Hani Nurlaeli Wijayanti, Cahya Edi Setyawan : Pandangan Stephen Krashen dalam Pemerolehan Bahasa dan Implikasinya dalam Pembelajaran Bahasa Arab

\section{DAFTAR PUSTAKA}

Alwazir Abdusshomad, AFFECTIVE FILTER TERHADAP PENGAJARAN BAHASA KEDUA (BAHASA ARAB), Jurnal Aviasi Langit Biru, Volume 5, Nomor 12, Oktober 2012.

Abdul Chaer dan Leoni Agustina, Sosiolinguistik: Perkenalan Awal, ( Jakarta: Rineka Cipta, 1995).

Brown H D, Pinciples of Language Learning and Teaching, fourth edition, (New York: Addison Wesley Longman Inc, 2000).

Fernandez, R. M., Singer, D. G., \& Revenson, T. A, A Piaget Primer: How a Child Thinks, Rocky Mountain Review of Language and Literature, 1981.

Johnson M, a Philosophy of Second Language Acquisition, (London: Yale University Press 2004).

Johnson K, An Introduction to Foreign Language Learning and Teaching, (England: Pearson Education Limited 2001).

Krashen S, Second Language "Standart for Success": Out of touch with Language Acquisition Research.

Lamb I, "Fudamental of Second Language Acquisition Theory and its Application to Beginning and Intermediate Language Teaching (on Stephen Krashen)" in The Journal of Tesol -France Volume VIII Number 3, Autumn 1988.

Krashen S, Principle and Practice in Second Language Acquisition, (University of Southem California: Pergamon Press Inc. 1982).

The McGill Conferece In Honour of Wallace E. Lambert, Bilingualism, Multiculturalism, and Second Language Learning, Hillsdale, (New Jersey: Lawrence Elbraum Associates, Inc, Publisher, 1991). 
Andri Warseto, Hani Nurlaeli Wijayanti, Cahya Edi Setyawan : Pandangan Stephen Krashen dalam Pemerolehan Bahasa dan Implikasinya dalam Pembelajaran Bahasa Arab

Richards \& Rodgers, Approachs and Methods in Language Teaching: A Description and Analisys, London: Cambridge Unversity Press, 1986.

Sunyono D, Psikolinguistik; Pengantar Pemahaman Bahasa Manusia, (Jakarta: Yayasan Obor Indonesia.).

Shafa, Teori Pemerolehan Bahasa dan Implikasinya dalam Pembelajaran, Jurnal Dinamika Ilmu, 2012.

Schütz, R, Teori Pemerolehan Bahasa, Assimilação Natural x Ensino Formal, English Made in Brazil, 2012.

Swastyastu L.T.J, Manfaat Media Pembelajaran dalam Pemerolehan Bahasa Kedua Anak Usia Dini, Pratama Widya : Jurnal Pendidikan Anak Usia Dini Volume 5, No. 1, April 2020. 